\title{
Impact of Noise Barriers on Air-Pollution Dispersion
}

\author{
Josef Brechler*, Vladimir Fuka \\ Department of Meteorology and Environment Protection, Faculty of Mathematics and Physics, Charles \\ University, Prague, Czech Republic \\ Email: ${ }^{*}$ josef.brechler@mff.cuni.cz
}

Received 10 December 2013; revised 10 January 2014; accepted 17 January 2014

Copyright (C) 2014 by authors and Scientific Research Publishing Inc.

This work is licensed under the Creative Commons Attribution International License (CC BY). http://creativecommons.org/licenses/by/4.0/

(c) $\underset{\mathrm{EY}}{0}$ Open Access

\begin{abstract}
The impact of noise barriers on gaseous air-pollution dispersion was examined using the highresolution CLMM (Charles University LES (Large Eddy Simulation) Microscale Model). The dispersion of a mixture of nitrogen oxides (denoted as $\mathrm{NO}_{\mathrm{X}}-\mathrm{a}$ mix of $\mathrm{NO}$ and $\mathrm{NO}_{2}$ ) was computed, providing the simulation in which wind direction is approximately perpendicular to the noise barriers. The barriers were assumed to be straight and infinitely long, with a height of $3 \mathbf{m}$. Dispersion of $\mathrm{NO}_{\mathrm{x}}$ was modeled for situations with no noise barriers along the highway, barriers on both sides, and for a single barrier on the upwind and downwind sides of the highway. The modelling results are presented and discussed in relation to previous studies and the implications of the results are considered for pollution barriers along highways.
\end{abstract}

\section{Keywords}

LES Modelling, Noise Barriers, Traffic Air-Pollution, Air-Pollution Transport and Dispersion

\section{Introduction}

Car traffic is a significant source of air pollution that can have a serious environmental impact, especially in densely settled urban areas. Cars are responsible for high concentrations of both gaseous air pollution and particulates. Nitrogen oxides ( $\mathrm{NO}$ and $\mathrm{NO}_{2}$ ) are the most important of the many air pollution agents that are emitted into the atmosphere. Air pollution from traffic poses a serious health threat to inhabitants living or working in the vicinity of busy roads. Although the concentration of air pollutants is usually measured, there are a limited number of monitoring stations within a city. Therefore, the spatial distribution of these agents is often modeled rather than measured, particularly for city management and municipal authorities. Many cities use the

*Corresponding author. 
ADMS-Urban software [1]. Other examples include the ATEM system used to generate maps of the concentration of air pollutants in Prague at ground level, as approved by the Czech Ministry of Environment, see [2]. Both these systems (and others used in Europe and the USA) are used to model concentrations over whole or large parts of cities. In contrast, this study will focus on issues at a local level in close proximity to busy roads and streets in settled areas on the outskirts of large cities. These areas are typically densely populated, with large groups of houses protected from traffic noise by noise barriers that also act as a barrier to air pollution from traffic.

This study examines the role of noise barriers as traffic pollution shields for the areas adjacent to busy roads by means of computer modelling using the LES (Large Eddy Simulation) approach. There have been few previous studies in which the transport and dispersion of air pollution have been assessed using LES modelling, particularly [3], [4] or [5]. However, these studies implemented LES modelling of air-pollution dispersion released from stationary point sources. Application of the LES approach to pollutant dispersion from vehicles is described in [6] but this study focused on the near-wake region close to the tip of exhaust pipes on light vehicles. Numerical simulation of turbulent dispersion from two-way roads using an LES approach is used in [7] and the problem of wind fields and dispersion of air pollution from vehicles in residential areas is addressed with an LES-based model in [8]. The wind field and pollutant dispersion in the downtown area of Macao is investigated using an LES-based model in [9]. The effect of trees on pollutant dispersion within a street canyon is modeled using an LES approach and validated with a wind tunnel experiment in [10]. All these previous studies address air pollution along roads or street canyons, but none has examined the impact of the noise barriers that can shelter surrounding areas from traffic emissions. This issue is addressed in the present study. Computational Fluid Dynamic (CFD) approaches have been used in previous studies, and results have been compared with measured data (e.g., [11], [12] or [13]). However, such studies used less sophisticated parameterization of turbulence than that used in this study,

The remainder of this manuscript is organized as follows. A brief description of the LES model is presented in Section 2, and the geometry of the problem, together with the boundary and initial conditions, is outlined in Section 3. The results of numerical simulation are presented and discussed in Section 4. Finally, concluding remarks are provided in Section 5.

\section{Description of the CLMM}

The CLMM (Charles University LES Microscale Model) has been developed at the Department of Meteorology and Environment Protection, Faculty of Mathematics and Physics at Charles University in Prague. Examples of previous use include study of the very stably stratified atmospheric boundary layer in [14] and mathematical simulation of the transport and dispersion of aerosol air pollution, see [15].

The basic set of model equations comprises an incompressible continuity equation, the Navier-Stokes equations for thermally stratified flow (the Boussinesq approximation), an equation for (potential) temperature change, and a transport equation(s) for a passive scalar(s). It is possible to include chemical reactions between different types of pollutants or transformation processes in the model. However, as the aim in this case is to simulate small-scale dynamics in high resolution, completed chemical reactions are likely to be minimal. Consequently, air pollution is denoted as $\mathrm{NO}_{\mathrm{x}}\left(\mathrm{a}\right.$ mix of $\mathrm{NO}$ and $\mathrm{NO}_{2}$ ) and is considered as a non-reacting passive scalar with constant composition.

$$
\begin{gathered}
\frac{\partial \overline{u_{i}}}{\partial x_{i}}=0 \\
\frac{\partial \overline{u_{i}}}{\partial t}+\frac{\partial \overline{u_{i} u_{j}}}{\partial x_{j}}=-\frac{\partial \bar{p}}{\partial x_{i}}+\frac{2 v \bar{S}_{i j}}{\partial x_{j}}+\frac{\partial \tau_{i j}}{\partial x_{j}}+\delta_{i 3} \frac{g}{\theta_{R E F}}\left(\bar{\theta}-\theta_{R E F}\right)+f \varepsilon_{i j 3} \bar{u}_{j} \\
\frac{\partial \bar{\theta}}{\partial t}+\frac{\partial \overline{u_{j} \theta}}{\partial x_{j}}=-\frac{\partial}{\partial x_{j}} q_{j} \\
\frac{\partial \bar{c}}{\partial t}+\frac{\partial \overline{u_{j} c}}{\partial x_{j}}=-\frac{\partial}{\partial x_{j}} s_{j}
\end{gathered}
$$


The set of filtered model equations is as follows:

where the overline indicates filtered quantities, and the subgrid turbulent stresses and fluxes are generally expressed as:

$$
\begin{aligned}
\tau_{i j} & =\overline{u_{i} u_{j}}-\overline{u_{i} u_{j}}, \\
q_{j} & =\overline{u_{j}} \bar{\theta}-\overline{u_{j} \theta}, \\
s_{j} & =\overline{u_{j} c}-\overline{u_{j} c} .
\end{aligned}
$$

In Equations (1)-(7), $t$ is time, $x_{i}$ are spatial coordinates, $u_{i}$ for $i=1,2,3$ denote velocity components, $p$ is pressure, $\theta$ is the potential temperature and $\theta_{R E F}$ is its reference value, $f$ is the Coriolis parameter, and $c$ is the passive scalar concentration. The symbol $\delta$ represents the Kronecker delta, and $\varepsilon_{i j k}$ is the alternating unit tensor, having a value equal to $1,-1$, or 0 depending on whether the indices ijk create even or odd permutations of the numbers 1,2 , and 3, and/or if any other indexes are alike. The symbol $\tau_{i j}$ denotes the turbulent sub-grid stress components, $q_{j}$ and $s_{j}$ are turbulent heat and air-pollution fluxes, respectively and these terms have to be modelled using the LES approach.

To model these sub-grid quantities, the concept of turbulent (or eddy) viscosity is used. It is assumed that the sub-grid stresses and fluxes are correlated to the strain rates and gradients of the filtered quantities (potential temperature, concentration) in the same way they are for molecular diffusion-see [16]. In the CLMM, the Vreman model [17] is used. In the Vreman approach, specified turbulence viscosity is of a general nature, in that it is only time dependent, in contrast to the more commonly used Smagorinsky model. This time dependence can be solved "dynamically" as suggested in [18], but here we employ the "time independent" variant. We chose not to use the Smagorinsky model because of the disadvantages outlined in [19] or in [20].

\section{Geometry of the Problem, and the Boundary and Initial Conditions}

The modelled section of road is a straight, four-lane highway, with two lanes in each direction. The lanes are separated in the middle by a median strip $1 \mathrm{~m}$ wide. Each lane is $6 \mathrm{~m}$ wide $(4 \mathrm{~m}$ of the lane itself and $2 \mathrm{~m}$ wide emergency stopping lane on the outer side of each lane). The total road width (and distance between barriers where present) is $25 \mathrm{~m}$. After consultation with the Road and Motorway Directorate of the Czech Republic (http://www.rsd.cz/en), the height of the noise barrier(s) was set to $3 \mathrm{~m}$ in suburban areas. The terrain near the road is assumed to be flat on both sides, and the road is level. When the impact of barriers is modeled, it is assumed that they are of infinite length - the impact of the end of the barrier on air-pollution dispersion has not been modeled. This geometry was chosen to simplify boundary conditions on the sides of the computational domain.

On the solid surfaces (bottom boundary and walls of the noise barrier(s)) the no slip boundary condition was applied. At the top of the domain, the free-slip condition was used, together with a 100-m-thick sponge layer immediately below this boundary. The wind direction is perpendicular to the axis of the road, and flow is fully developed on the inflow boundary using the approach outlined in [21]. At the outflow, an open boundary is applied for flow directed normal to the boundary. To ensure that this condition is met, an additional 100-m-thick buffer zone is added to the domain immediately in front of the boundary. The geometry of the problem allowed for periodic boundaries on the side of the domain, parallel to the incoming wind direction.

Neutral vertical temperature stratification was chosen for the simulation. The wind speed was set to $5 \mathrm{~ms}^{-1}$ at the anemometric height (10 $\mathrm{m}$ above the terrain), and the vertical gradient of the potential temperature was set to $0 \mathrm{Km}^{-1}$. The wind speed at the inflow boundary followed a logarithmic profile with a roughness length on the order of $10^{-2} \mathrm{~m}$. The wind flow was fully developed due to the application of the inflow condition described in [21].

The emission rate of $\mathrm{NO}_{\mathrm{x}}$ used in this model was set to $0.2255 \mathrm{~g} / \mathrm{s} / \mathrm{km}$ per lane of traffic, as suggested by the Road and Motorway Directorate. The composition of $\mathrm{NO}_{\mathrm{x}}$ corresponds to $70 \% \mathrm{NO}_{2}$ and $30 \% \mathrm{NO}$, and this remains constant over the time and distance modelled.

\section{Results and Discussion}

Initially, the reference result was computed detailing the situation without barriers. Subsequently, the situations 
with barriers on both sides of the road and with only one barrier (either upwind or downwind) were computed. Figure 1 shows the circulation scheme when two barriers are present. Figure 2 depicts the circulation scheme in the same atmospheric conditions with only one barrier. As this situation corresponds to the presence of a barrier on flat terrain, the pattern of the circulation scheme is not dependent on which side of the road the barrier is placed on with reference to wind direction. Both Figure 1 and Figure 2 show the time-averaged wind fields with averaging interval of $200 \mathrm{~s}$.

Figure 3 shows the spatial distribution of $\mathrm{NO}_{\mathrm{x}}$ concentrations $\left(\right.$ in $\mu \mathrm{g} \cdot \mathrm{m}^{-3}$ ) near the road for the reference situation. It is evident that traffic pollution remains concentrated near the ground. This area of high concentration spans a considerable distance (in excess of $200 \mathrm{~m}$ ) from the road, as there is no obstacle to prevent its transport downwind. Figure 4 shows the concentration distribution in a vertical cross-section perpendicular to the same road, but with 3-m-high barriers on both sides. All other parameters remained unchanged. A comparison of

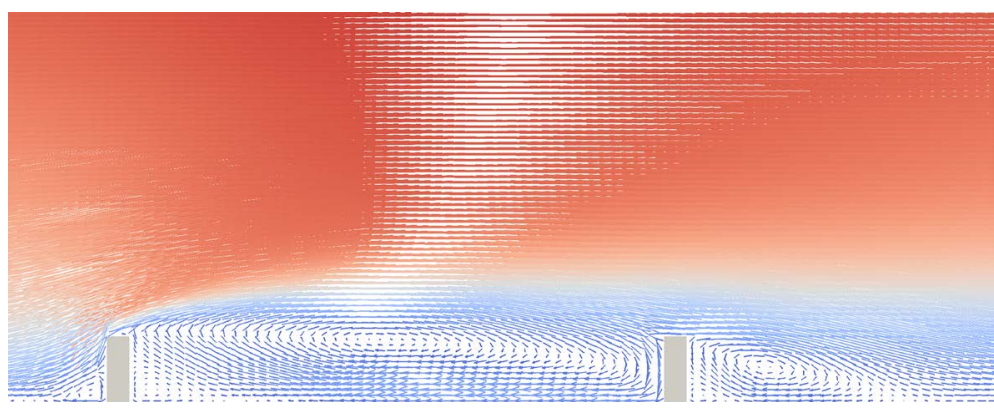

Figure 1. Time average (200 s) of circulation past two barriers.

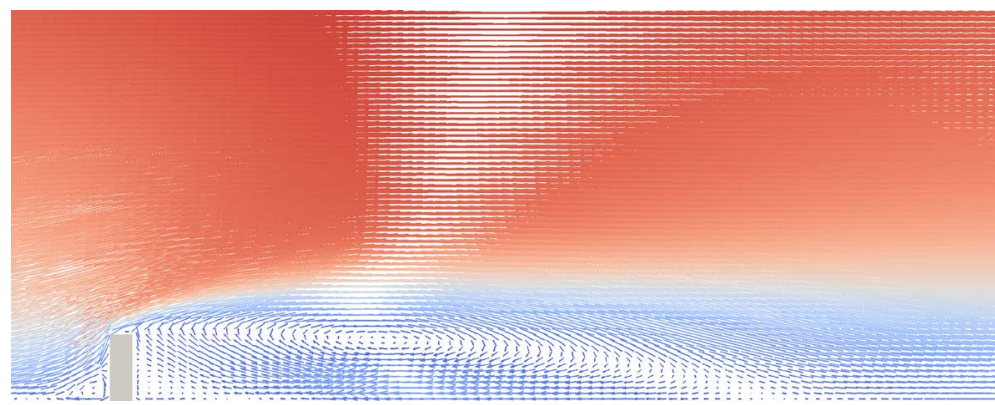

Figure 2. Time average (200 s) of circulation past one barrier.

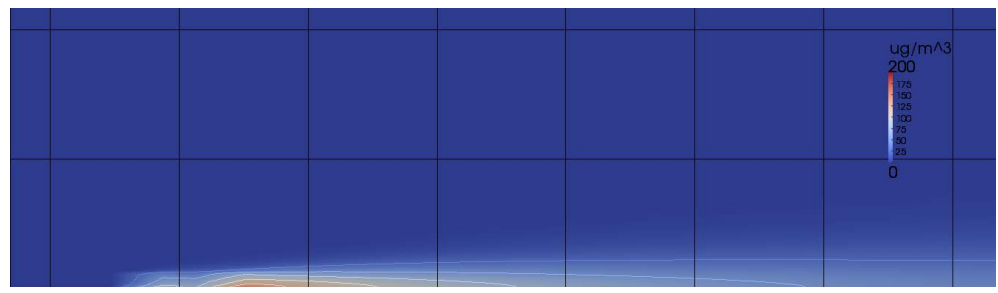

Figure 3. Time average of the vertical cross section of $\mathrm{NO}_{\mathrm{X}}$ concentration spatial distribution (in $\mu \mathrm{g} \cdot \mathrm{m}^{-3}$ ) in the case of none barrier.

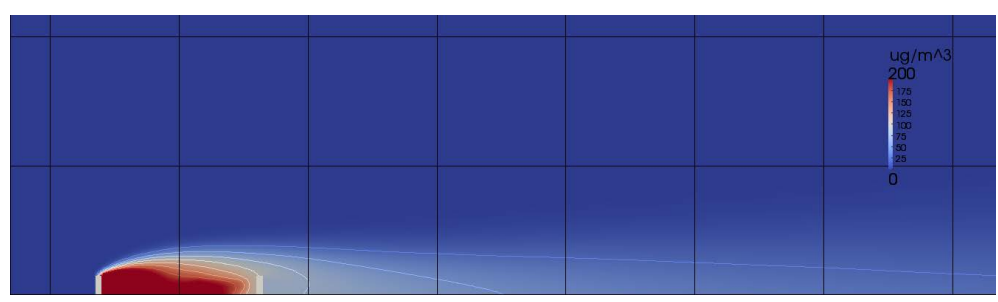

Figure 4. The same as in Figure 3 but for the case of two barriers. 
Figure 3 and Figure 4 shows that the area affected by car emissions does not extend a considerable distance in the lee of the road when the barriers are present. Instead, $\mathrm{NO}_{\mathrm{x}}$ is highly concentrated between the barriers and in the area immediately behind the barrier on the leeward side, and decreases much more rapidly with distance in comparison with Figure 3. High concentrations of $\mathrm{NO}_{\mathrm{x}}$ are distributed over a greater vertical area when barriers are present, due to the recirculation of air invoked by the barriers.

Figure 5 shows the spatial distribution of $\mathrm{NO}_{\mathrm{x}}$ concentration when the noise barrier is located on the upwind side of the road. The distribution shown in this figure is very similar to that in Figure 4. The impact of the upwind barrier on the flow and thus also on the concentration distribution can be seen more clearly in Figure 7 and Figure 8, which show the pollutant concentration profiles at 1.5 and $3.0 \mathrm{~m}$ above the surface.

Figure 6 shows a vertical cross-section of $\mathrm{NO}_{\mathrm{x}}$ concentration when the noise barrier is located in the lee of the road. The area of high $\mathrm{NO}_{\mathrm{x}}$ concentration is located on the road in front of the noise barrier, but also behind the road where recirculation has trapped pollution in the lee of the barrier. This can be seen more clearly in Figure 7, which shows the concentration profile as a function of distance from the axis of the median strip $(x=0)$. Profiles of the concentrations are shown at $1.5 \mathrm{~m}$ above the ground.

Figure 7 shows concentration profiles in the following cases: no barrier (solid line), upwind barrier (long dashed line) downwind barrier (short dashed line), and both barriers (dotted line). These conventions are used for all the following figures showing horizontal and vertical concentration profiles. Figure 7 shows that the highest concentrations at surface level in the road area occur when two noise barriers are present, and when one upwind noise barrier is present. When there are no barriers present, or when there is a barrier on the downwind side of the road only, the peak concentration just above the road is much lower and shifted downwind. However, concentrations up to approximately $100 \mathrm{~m}$ from the road are higher when there is only a downwind barrier, or over the whole downwind area when no barrier is present. The shapes of the curves indicate that recirculation zones behind the barriers and over the lanes form secondary concentration maxima. In situations where two barriers or one upwind barrier are present, secondary maxima are located downwind of the primary maxima. Conversely, where there are no barriers or one downwind barrier, secondary maxima are located upwind of the primary maxima. Most importantly, when there are no barriers or only a leeward side barrier, concentrations of $\mathrm{NO}_{\mathrm{x}}$ above the road itself are relatively low, but are higher adjacent to the road. This extends for $100 \mathrm{~m}$ when there is a leeward barrier, and over the whole modeled area when there are no barriers. The low concentrations occur as a result of good ventilation in the area above the road. In the case of a barrier on both sides, the maximum concentration is, approximately, $545 \mu \mathrm{g} \cdot \mathrm{m}^{-3}$. This is slightly lower, but of the same magnitude, as the concentration with one barrier on the upwind side.

Figure 8 shows the concentration profiles depicted in Figure 7, but at $3 \mathrm{~m}$ above the terrain. Concentrations are lower but have similarly shaped distributions as those in Figure 7. However, there is one exception. Where

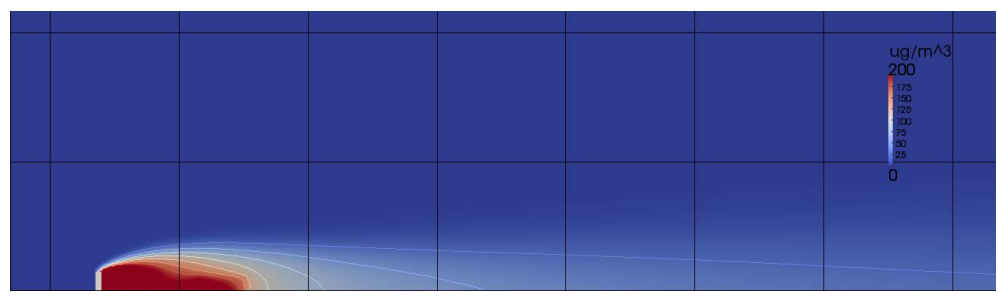

Figure 5. The same as in Figure 3 but for the case of one upwind located barrier.

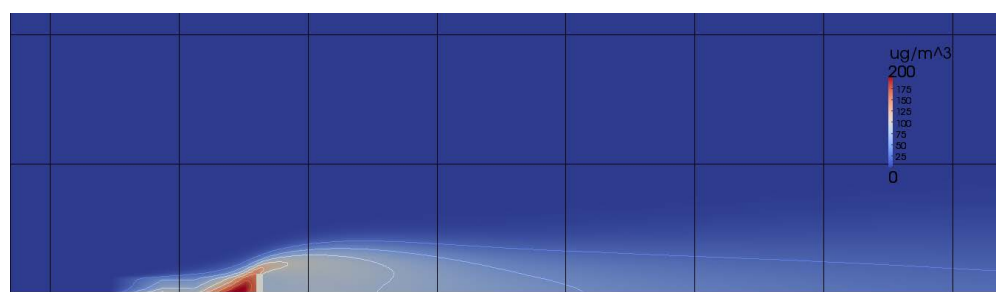

Figure 6. The same as in Figure 3 but for the case of one downwind located barrier. 


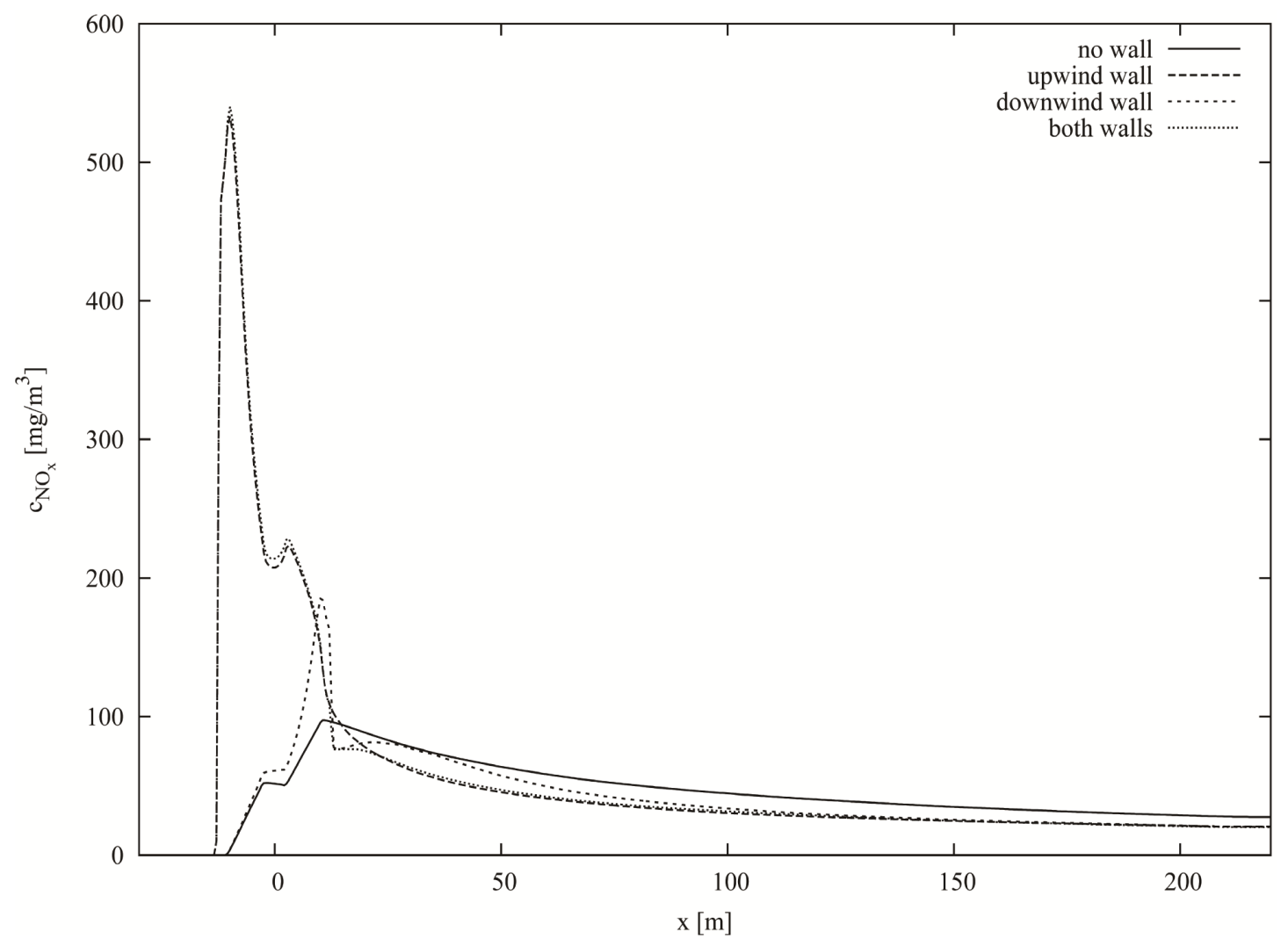

Figure 7. Time averages of the horizontal $\mathrm{NO}_{\mathrm{X}}$ concentration profiles (in $\mu \mathrm{g} \cdot \mathrm{m}^{-3}$ ) at the height $1.5 \mathrm{~m}$ above ground.

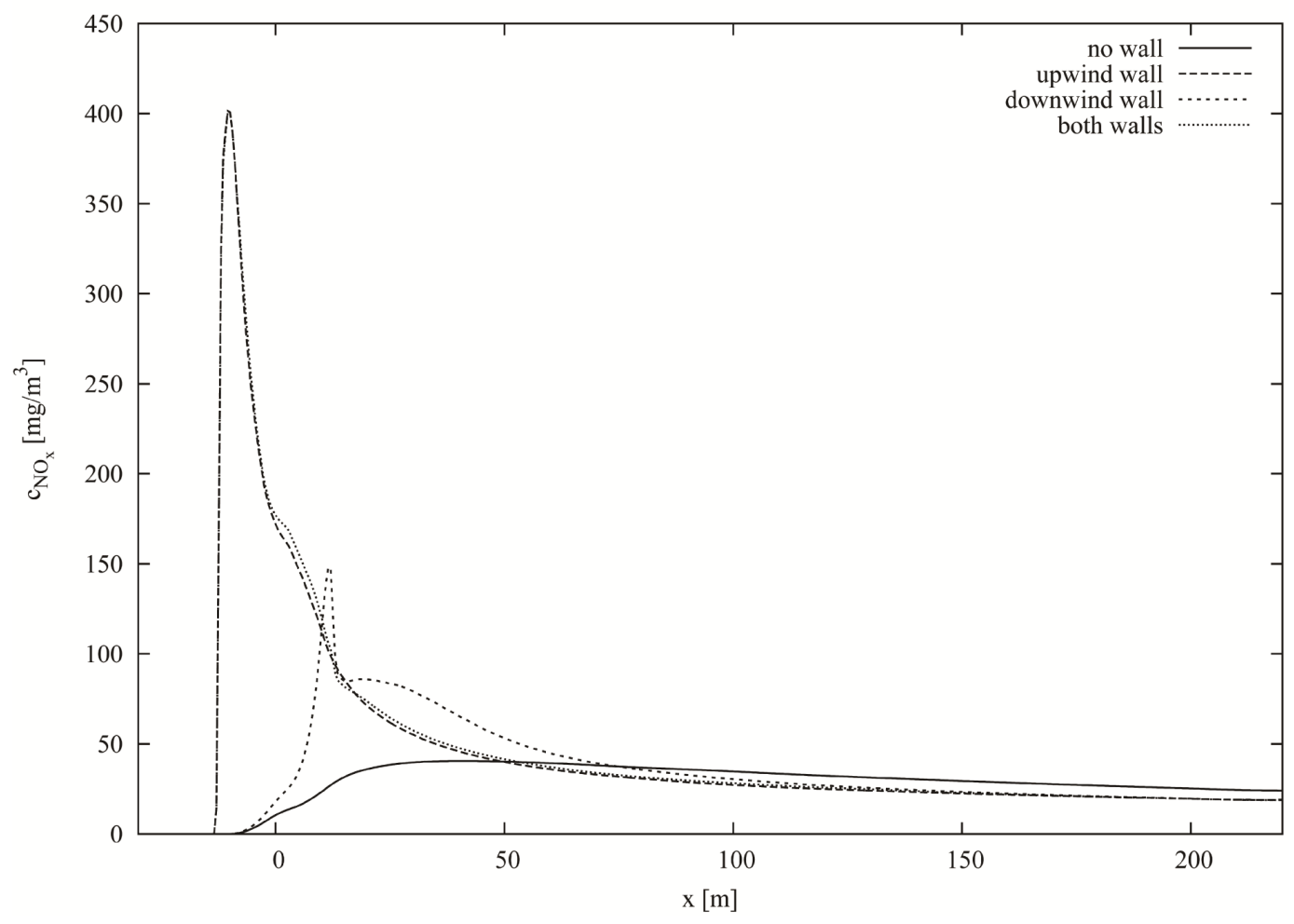

Figure 8. The same as in Figure 7 but for the height $3 \mathrm{~m}$ above ground. 
there is one leeward barrier, the horizontal concentration profile lines are much smoother, indicating that the impacts of recirculation behind the barrier are less pronounced at this height.

The vertical distributions of concentrations at a point located $22.5 \mathrm{~m}$ downwind of the road axis are shown in Figure 9. This demonstrates that the presence of any barrier, regardless of location, results in a decrease in concentration at ground level and an increase in the height at which higher concentrations occur, due to blocking effects and recirculation behind the barrier. The highest ground concentrations at this location were recorded when no barriers were present, but this changes at $2.0-2.5 \mathrm{~m}$ above the surface.

Figure 10 and Figure 11 show snapshots of the concentration distributions in the computational domain when $3-\mathrm{m}$ barriers are present on both sides of the highway. Figure 10 shows the iso-surface of the $25 \mu \mathrm{g} \cdot \mathrm{m}^{-3}$ concentration, and Figure 11 shows the iso-surface of the $125 \mu \mathrm{g} \cdot \mathrm{m}^{-3}$ concentration.

It is important to note that throughout the modelling process, the layout of the simulation was simplified, as buildings and vegetation were not taken into account and terrain was assumed to be flat. Furthermore, it was assumed that emissions only originated from traffic on the segment on the road being examined.

When a barrier is present, the pollutant distribution is affected by the recirculation zone, primarily occurring on the leeward side of the highway. Our results characterizing the recirculation zone (Figure 2) show good qualitative agreement with previous studies, such as [12] or [13]. It is also important to recognize that the results of our computations show flow occurring above the 3-m-high barrier.

Our results show that placing barriers on both sides of the highway produces the most advantageous result, closely followed by locating a single barrier on the upwind side. As expected, the least desirable result occurred when there were no barriers. The negative impact of recirculation when a barrier is located on the leeward side of the highway is interesting, as it concentrates pollution in close proximity behind the barrier. It was expected

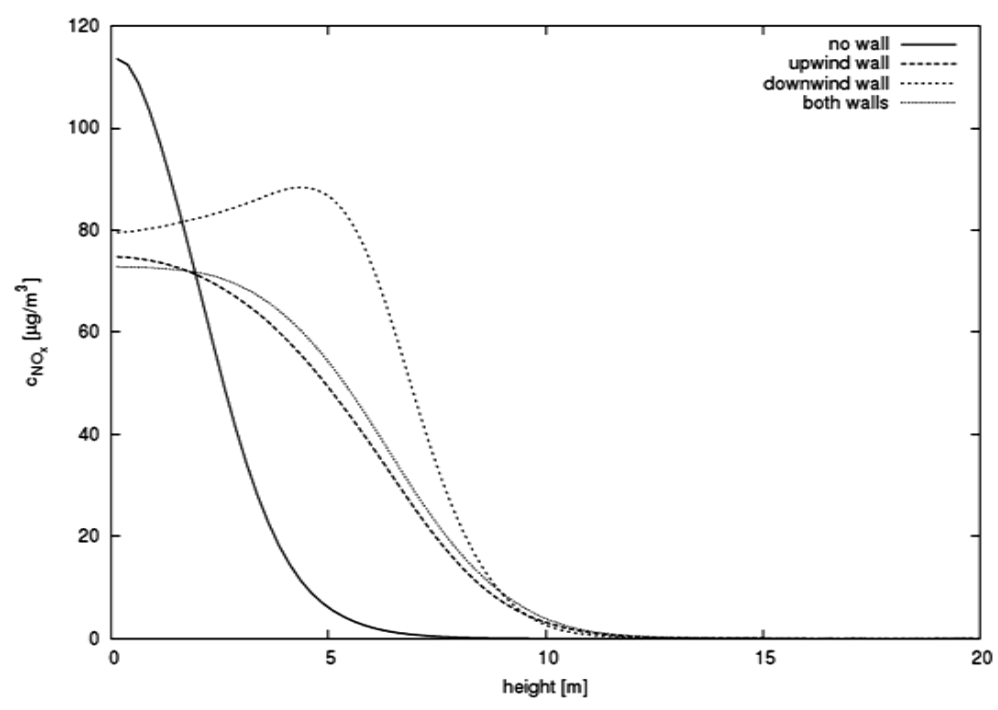

Figure 9. Time averages of the vertical $\mathrm{NO}_{\mathrm{X}}$ concentration profiles (in $\mu \mathrm{g} \cdot \mathrm{m}^{-3}$ ) at the location $10 \mathrm{~m}$ from the downwind edge of the highway.

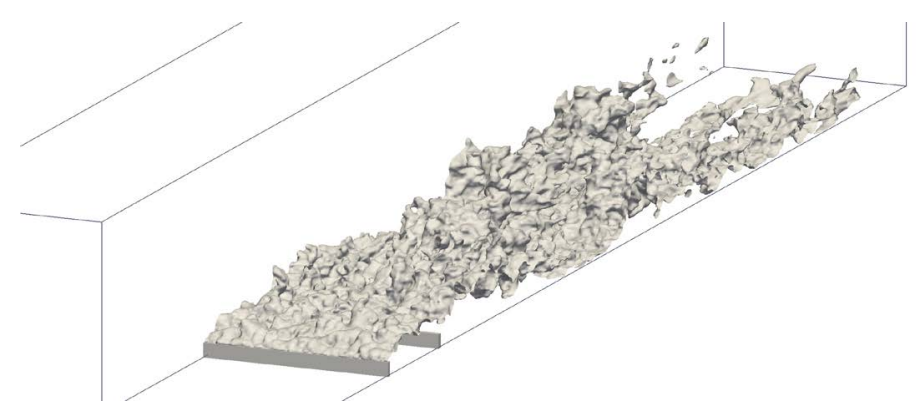

Figure 10. Snapshot of the $\mathrm{NO}_{\mathrm{X}}$ concentration field spatial distribution. The iso-surface of $25 \mu \mathrm{g} \cdot \mathrm{m}^{-3}$ concentration is shown. 


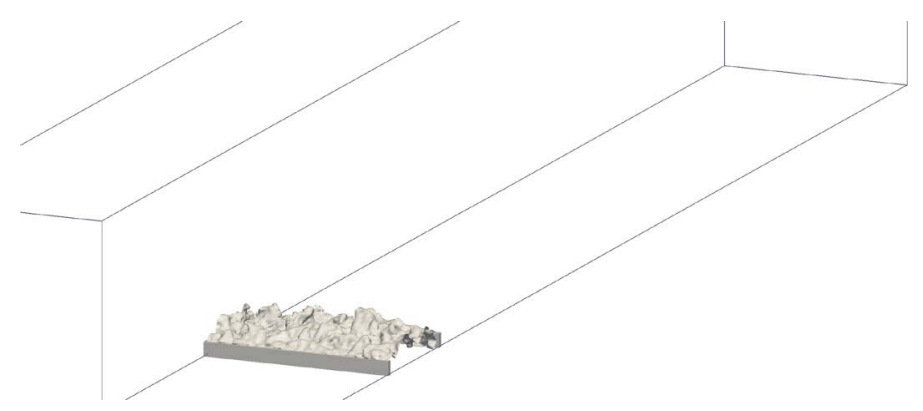

Figure 11. The same as in Figure 10 but for the iso-surface of $125 \mu \mathrm{g} \cdot \mathrm{m}^{-3}$ concentration.

that a barrier on the leeward side would prevent accumulation of gaseous pollutants behind it, but results showed that it provided little advantage over having no barrier.

Our results qualitatively correspond to the model study presented in [22] and to measurements detailed in [23]. Qualitative agreement can also be found between results shown here and those for the ultrafine fraction of particulates described in [24]. In [25] a horizontal profile of air pollutants in wind tunnel measurements shows that the highest concentrations occur on flat terrain with no barrier, or elevated roads with sloping barriers. Although we have not tested elevated roads or sloping barriers, these results show general agreement with those of the present study. The quantitative results of all these studies differ, as different emission rates were used, and this difference can also be seen when comparing our results with those reported in [26]. Furthermore, these previous studies used a barrier height of $6 \mathrm{~m}$, whereas we used a height of $3 \mathrm{~m}$, as recommended by the Road and Motorway Directorate.

\section{Concluding Remarks}

We simulated the impact of noise barriers on air-pollution dispersion. To do this, relatively simple conditions were chosen: a straight section of four-lane highway on flat terrain with no surrounding buildings or vegetation. The wind direction was perpendicular to the highway direction and thermal stratification was neutral.

The results show that barriers, particularly when located on the upwind side or on both sides of a highway, improve environment conditions. Concentrations of pollutants in the lee of the highway are lower when there are no barriers, or when a barrier is located on the downwind side of the highway. This effect is due to recirculation, which traps pollutants close behind the barrier. When a barrier is present on the upwind side of the highway, the concentration at and just above the road surface is increased, but lowered on the leeward side of the highway. Recirculation behind the leeward-side barriers also increases the pollutant concentration behind the barrier up to $80 \mathrm{~m}$ from the highway side in comparison with barriers on both sides or on the upwind side. When there are no barriers, concentrations at the highway surface and just above are the lowest of all situations due to the increased ventilation. However, a much greater area is subject to increased concentrations of pollutants.

The results show that although barriers on both sides of a highway provide the ideal solution, the use of only one barrier located on the upwind side provides an almost identical result at a much lower cost. However, implementing this lower-cost solution is only possible in settings where the orography or geometry of obstacles such as buildings ensures that the wind direction is relatively constant. If this is not the case, barriers on both sides of the highway may have to be installed to effectively shield the urban population from increased air pollution near highways.

\section{Acknowledgements}

This work was supported by the Czech Ministry of Education, Youth and Sports under the framework of the research plan MSM0021620860, by the Road and Motorway Directorate of the Czech Republic, and by the company ATEM, s.r.o.

\section{References}

[1] Stocker, J., Hood, C., Carruthers, D. and McHugh, C. (2011) ADMS-Urban: Developments in Modelling Dispersion 
from the City Scale to the Local Scale. International Journal of Environment and Pollution, 50, 308-316.

[2] Brechler, J. (2000) Model Assessment of Air-Pollution in Prague. Environmental Monitoring and Assessment, 65, 269-276. http://dx.doi.org/10.1023/A:1006490627003

[3] Nakayama, H. and Nagai, H. (2009) Development of Local-Scale High-Resolution Atmospheric Dispersion Model Using Large-Eddy Simulation: Part 1: Turbulent Flow and Plume Dispersion over a Flat Terrain. Journal of Nuclear Science and Technology, 46, 1170-1177. http://dx.doi.org/10.1080/18811248.2009.9711630

[4] Nakayama, H., Takemi, T. and Nagai, H. (2009) LES Analysis of Plume Dispersion through Urban-Like Building Arrays. Proceedings of the 7th International Conference on Urban Climate, Yokohama, 29 June-3 July 2009, 4p.

[5] Nakayama, H. and Nagai, H. (2010) Large-Eddy Simulation on Turbulent Flow and Plume Dispersion over a 2-Dimensional Hill. Advances in Science \& Research (Internet), 4, 71-76. http://dx.doi.org/10.5194/asr-4-71-2010

[6] Dong, G. and Chan, T.L. (2006) Large Eddy Simulation of Flow Structures and Pollutant Dispersion in the Near-Wake Region of a Light-Duty Diesel Vehicle. Atmospheric Environment, 40, 1104-1116. http://dx.doi.org/10.1016/j.atmosenv.2005.11.004

[7] Yasuda, R., Miyajima, T. and Yoshida, A. (2007) Numerical Simulation of Turbulent Dispersion on a Two-Way Facing Traffic Road. Proceedings of the 11th International Conference on Harmonisation within Atmospheric Dispersion Modelling for Regulatory Purposes, Cambridge, 2-5 July 2007, 192-196.

[8] Cui, G., Shi, R., Xu, C., Zhang, Z. and Wang, Z. (2009) Large Eddy Simulation of Wind Field and Traffic Pollutant Dispersion in a Residence Area. Proceedings of the 6th International Symposium on Turbulence and Shear Flow Phenomena, Seoul, 22-24 June 2009, 1275-1278.

[9] Liu, Y.S., Cui, G.X., Wang, Z.S. and Zhang, Z.S. (2011) Large Eddy Simulation of Wind Field and Pollutant Dispersion in Downtown Macao. Atmospheric Environment, 45, $2849-2859$. http://dx.doi.org/10.1016/j.atmosenv.2011.03.001

[10] Salim, S.M., Chan, A., Buccolieri, R., Di Sabatino, S. and Cheah, S.C. (2010) Large Eddy Simulation of the Aerodynamic Effects of Trees on Pollutant Concentration in Street Canyons. Procedia Environmental Sciences 4, Urban Environmental Pollution 2010, 17-24.

[11] Bitog, J.P., Lee, I.B., Shin M.H., Hong, S.W., Hwang, H.S., Seo, I.H., Yoo, J.I., Kwon, K.S., Kim, Y.H. and Han, J.W. (2009) Numerical Simulation of an Array of Fences in Saemangeum Reclaimed Land. Atmospheric Environment, 43, 4612-4621. http://dx.doi.org/10.1016/j.atmosenv.2009.05.050

[12] Bowker, G.F., Baldauf, R., Isakov, V., Khlystov, A. and Petersen, W. (2007) The Effects of Roadside Structures on the Transport and Dispersion of Ultrafine Particles from Highways. Atmospheric Environment, 41, 8128-8139. http://dx.doi.org/10.1016/j.atmosenv.2007.06.064

[13] Hagler, G.S.W., Tang, W. Freeman, M.J., Heist, D.K., Perry, S.G. and Vette, A.F. (2011) Model Evaluation of Roadside Barrier Impact on Near-Road Air Pollution. Atmospheric Environment, 45, 2522-2530. http://dx.doi.org/10.1016/j.atmosenv.2011.02.030

[14] Fuka, V. and Brechler, J. (2011) Large Eddy Simulation of the Stable Boundary Layer. In: Fort, J., Fuerst, J., Halama, J., Herbin, R. and Hubert, F., Eds., Finite Volumes for Complex Applications VI. Problems \& Perspectives. FVCA 6 International Symposium, Prague, 6-10 June 2011, Springer, 485-493.

[15] Fuka, V. and Brechler, J. (2012) Large Eddy Simulation Modelling of the Dispersion of Radioactive Particulate Matter. International Journal of Environment and Pollution, 48, 156-163. http://dx.doi.org/10.1504/IJEP.2012.049662

[16] Lesieur, M., Métais, O. and Comte, P. (2005) Large-Eddy Simulations of Turbulence. Cambridge University Press, Cambridge. http://dx.doi.org/10.1017/CBO9780511755507

[17] Vreman, A.W. (2007) Subgrid-Modeling in Large-Eddy Simulation of Complex Flows. In: Oberlack, M., et al., Eds., Progress in Turbulence II, Springer-Verlag, Heidelberg, 301-304.

[18] You, D. and Moin, P. (2007) A Dynamic Global-Coefficient Subgrid Scale Eddy-Viscosity Model for Large-Eddy Simulation in Complex Geometries. Physics of Fluids, 19, Article ID: 065110. http://dx.doi.org/10.1063/1.2739419

[19] Geurts, B.J. (2004) Elements of Direct and Large-Eddy Simulation. 1st Edition, Edwards, USA.

[20] Iizuka, S. and Kondo, H. (2006) Large-Eddy Simulations of Turbulent Flow over Complex Terrain Using Modified Static Eddy Viscosity Models. Atmospheric Environment, 40, 925-935. http://dx.doi.org/10.1016/j.atmosenv.2005.10.014

[21] Xie, Z.T. and Castro, I.P. (2008) Efficient Generation of Inflow Conditions for Large Eddy Simulation of Street-Scale Flows. Flow, Turbulence and Combustion, 81, 449-470. http://dx.doi.org/10.1007/s10494-008-9151-5

[22] Heist, D.K., Perry, S.G. and Brixey, L.A. (2009) A Wind Tunnel Study of the Effect of Roadway Configurations on the Dispersion of Traffic-Related Pollution. Atmospheric Environment, 43, 5101-5111. 
http://dx.doi.org/10.1016/j.atmosenv.2009.06.034

[23] Ning, Z., Hudda, N., Daher, N., Kam, W., Herner, J., Kozawa, K., Mara, S. and Sioutas, C. (2010) Impact of Roadside Noise Barriers on Particle Size Distributions and Pollutants Concentrations near Freeways. Atmospheric Environment, 44, 3118-3127. http://dx.doi.org/10.1016/j.atmosenv.2010.05.033

[24] Baldauf, R., Thoma, E., Khlystov, A., Isakov, V., Bowker, G., Long, T. and Snow, R. (2008) Impacts of Noise Barriers on Near-Road Air Quality. Atmospheric Environment, 42, 7502-7507. http://dx.doi.org/10.1016/j.atmosenv.2008.05.051

[25] Baldauf, R., Watkins, N., Heist, D., Bailey, C., Rowley, P. and Shores, R. (2009) Near-Road Air Quality Monitoring: Factors Affecting Network Design and Interpretation of Data. Air Quality, Atmosphere \& Health, 2, 1-9. http://dx.doi.org/10.1007/s11869-009-0028-0

[26] Zhang, Y., Ying, Q., Lv, J. and Kota, S.H. (2010) Methodology and Guidelines for Regulating Traffic Flows under Air Quality Constraints in Metropolitan Areas. Final Report of DOT Grant No, DTRT06-G-0044, UTCM Project \#08-04-17, University Transportation Center for Mobility, Texas Transportation Institute. 